\title{
A comparative study of the in vitro activity of iodopropynyl butylcarbamate and amphotericin B against Prototheca spp. isolates from European dairy herds
}

\author{
T. Jagielski, ${ }^{1}{ }^{1}$ Z. Bakuła, ${ }^{*}$ S. Di Mauro,† C. Casciari,‡ V. Cambiotti,‡ H. Krukowski,§ B. Turchetti,† M. Ricchi,\# \\ E. Manuali, $\ddagger$ and P. Buzzini ${ }^{1}$ \\ *Department of Applied Microbiology, Institute of Microbiology, Faculty of Biology, University of Warsaw, Warsaw 02-096, Poland \\ †Department of Agricultural, Food and Environmental Sciences, Industrial Yeasts Collection DBVPG, University of Perugia, Perugia, 06121 Italy \\ ‡lstituto Zooprofilattico Sperimentale dell'Umbria e delle Marche, Perugia, 06121 Italy \\ $\S$ Department of Animal Hygiene and Environment, Faculty of Biology, Animal Sciences and Bioeconomy, University of Life Sciences in Lublin, \\ Lublin 20-950, Poland \\ \#Istituto Zooprofilattico Sperimentale della Lombardia e dell'Emilia Romagna, Piacenza, 29027 Italy
}

\begin{abstract}
The objective of this study was to assess the in vitro effect of iodopropynyl butylcarbamate (IPBC) and amphotericin B (AMB) on Prototheca zopfii genotype 2 and Prototheca blaschkeae isolates recovered from dairy herds of Belgium, France, Italy, Germany, and Poland. The combination of IPBC with AMB on Prototheca isolates and toxicity of IPBC to the bovine mammary epithelial cells were also evaluated. The in vitro activity of IPBC and AMB against 96 isolates of $P$. zopfii genotype 2 and 42 isolates of $P$. blaschkeae was performed. Minimum inhibitory concentrations (MIC) and minimum algicidal concentrations (MAC) of IPBC and AMB were determined. To determine any synergistic, additive, or antagonistic effect of the combination of IPBC and AMB, 2-dimensional checkerboard combination tests were also performed to calculate fractional inhibitory concentrations. Cytotoxicity analysis of IPBC to the bovine mammary epithelial cell line was performed using a 3-(4,5-dimethyl-2-thiazol-2yl)-2,5diphenyl tetrazolium bromide (MTT) assay. The MIC for 50 and $90 \%$ of isolates $\left(\mathrm{MIC}_{50}\right.$ and $\mathrm{MIC}_{90}$, respectively) for IPBC were 4 and $8 \mathrm{mg} / \mathrm{L}$ versus 0.5 and 1 $\mathrm{mg} / \mathrm{L}$ for AMB, respectively. The MIC profiles differed between $P$. zopfii genotype 2 and $P$. blaschkeae, with the latter species being more susceptible to both compounds. The $\mathrm{MIC}_{50}$ and $\mathrm{MIC}_{90}$ of IPBC were 4 and 8 $\mathrm{mg} / \mathrm{L}$ for $P$. zopfii genotype 2 and 1 and $2 \mathrm{mg} / \mathrm{L}$ for $P$. blaschkeae, respectively. The $\mathrm{MIC}_{50}$ and $\mathrm{MIC}_{90}$ of $\mathrm{AMB}$ were both $1 \mathrm{mg} / \mathrm{L}$ for $P$. zopfii genotype 2 and 0.25 and $1 \mathrm{mg} / \mathrm{L}$ for P. blaschkeae, respectively. Both IPBC and
\end{abstract}

Received January 14, 2017.

Accepted May 24, 2017.

${ }^{1}$ Corresponding authors: pietro.buzzini@unipg.it and t.jagielski@ biol.uw.edu.pl
AMB exhibited the ability to kill Prototheca spp. The MAC for $90 \%$ of isolates of IPBC was twice the $\mathrm{MIC}_{90}$, whereas an 8-fold increase of the $\mathrm{MIC}_{90}$ was algicidal in the case of AMB. Overall, the combined use of IPBC and AMB exhibited an increased algicidal effect, albeit the fractional inhibitory concentration index showed synergistic activity only against $3 P$. zopfii genotype 2 isolates. For all the remaining isolates $(87.5 \%)$, this combination produced only an additive effect. The MTT assay results showed both IPBC and AMB, at the concentrations employed in the study, to be nontoxic to the epithelial mammary gland cells (cell viability >90\%). Notably, only IPBC at the highest concentration (i.e., $8 \mathrm{mg} / \mathrm{L}$ ) exerted a slight cytotoxic effect on the cell line tested (mean cell viability: $88.54 \pm 3.88$ and $90.66 \pm$ 3.0, after 2 and $4 \mathrm{~h}$ of MTT treatment, respectively). The anti-Prototheca activity of IPBC was here demonstrated for the first time. In addition, the combined use of IPBC with AMB enhanced each other's effect, creating an additive rather than synergistic interaction. Both agents, used at concentrations corresponding to MIC values against Prototheca spp., showed no toxic effect for the mammary epithelial cells. In conclusion, IPBC, used either alone or in combination with AMB, can be considered a promising option in the treatment armamentarium for protothecal mastitis in dairy cows. Key words: Prototheca sp., iodopropynyl butylcarbamate, amphotericin B, minimum inhibitory concentration, 3-(4,5-dimethyl-2-thiazol-2yl)-2,5diphenyl tetrazolium bromide assay

\section{INTRODUCTION}

The genus Prototheca includes unicellular, yeastlike, achloric microalgae, phylogenetically related to Chlorella spp. Seven species are currently accepted: Prototheca blaschkeae, Prototheca stagnora, Prototheca 
ulmea, Prototheca wickerhamii, Prototheca zopfii, Prototheca cutis, and Prototheca miyajii (Roesler et al., 2006; Satoh et al., 2010; Jagielski et al., 2012; Masuda et al., 2016), some of which are implicated in both human and animal disease (Janosi et al., 2001; Tsuji et al., 2006; Jagielski and Lagneau, 2007; Stenner et al., 2007). Prototheca zopfii genotype 2 and P. blaschkeae have been reported as the causative agents of bovine mammary protothecosis (mastitis; Roesler et al., 2006; Jagielski and Lagneau, 2007; Ricchi et al., 2013). The disease has been recognized globally but only since the late 1990s has it received serious attention by the veterinary community due to its escalating occurrence (Lagneau, 1996; Aalbaek et al., 1998; Castagna de Vargas et al., 1998; Janosi et al., 2001; Buzzini et al., 2004; Scaccabarozzi et al., 2008; Ricchi et al., 2010; Jagielski et al., 2011; Gao et al., 2012; Ricchi et al., 2013; Bozzo et al., 2014; Shahid et al., 2016).

The protothecal mastitis infections develop at various stages of lactation and in dry periods and can be restricted to the udder or become disseminated to the lymph nodes. The disease is usually paucisymptomatic, with an undetectable onset and slowly progressing course. The identification, removal, and slaughter of infected cows are routinely recommended to halt the transmission and contain the outbreak in the herd. Further measures for controlling bovine protothecosis include the improvement of the hygiene conditions in herds, milking parlor, and milking devices (Janosi et al., 2001). Treatment of protothecosis is a key problem because several studies have reported low susceptibility or resistance of $P$. zopfii genotype 2 and occasionally $P$. blaschkeae to a broad range of antimicrobials currently employed in human and veterinary medicine (Janosi et al., 2001; Buzzini et al., 2008; Jagielski et al., 2012).

All the aforesaid issues have recently stimulated the increasing interest toward the in vitro activity of various chemicals against Prototheca spp. (Melville et al., 2002; Marques et al., 2006; Buzzini et al., 2008; Cunha et al., 2010; Jagielski et al., 2012; Tomasinsig et al., 2012; Chang et al., 2013; Bouari et al., 2014; Grzesiak et al., 2016; Morandi et al., 2016).

Among different sanitizing agents used in the dairy industry, compounds containing iodine are recognized as highly efficient. Iodine exhibits a strong cell-penetrating power, induces protein precipitation and oxidation denaturation of essential proteins and enzymes, thus interfering with essential metabolic reactions of microorganisms. In dairy farms, solutions of 0.1 and 0.5 to $1 \%$ iodine have routinely been used in pre- and postmilking washing (dipping), respectively, for the control of bovine mastitis (Salerno et al., 2010; Lassa et al., 2011; Sobukawa et al., 2011; Gonçalves et al., 2015).
Iodopropynyl butylcarbamate (IPBC，3-iodoprop2-yn-1-yl butylcarbamate) is a water-soluble, iodinecontaining carbamate derivative, which exhibits a strong antifungal activity. Iodopropynyl butylcarbamate has been used for years as an industrial fungicide, mainly for wood and paint preservation. Iodopropynyl butylcarbamate has proven to be safe in terms of toxicity or skin irritancy when used at concentrations less than $0.1 \%$, and since the mid-1990s, its application has been expanded to a variety of cosmetic products, including shampoos, lotions, powders, makeup, baby products, contact lenses, and moistened toilet tissue (Steinberg, 2002; Maier et al., 2009).

Out of the antibiotics whose in vitro activity against Prototheca spp. has repeatedly been studied, amphotericin B (AMB), a polyene, macrolide antibiotic, has consistently produced the best results (Melville et al., 2002; Buzzini et al., 2008; Lassa et al., 2011; Jagielski et al., 2012). Amphotericin B has a long-standing reputation as an effective drug in the treatment of cutaneous and severe systemic mycoses (Bennet, 2005; Sweetman, $2005)$.

To the authors' knowledge, the anti-Prototheca activity of IPBC has never been evaluated before. Accordingly, the present study reports the in vitro effect of IPBC on P. zopfii genotype 2 and P. blaschkeae isolates. The combination of IPBC with AMB was also evaluated.

\section{MATERIALS AND METHODS}

\section{Prototheca spp. Isolates and Bovine Mammary Epithelial Cells}

Ninety-six isolates of $P$. zopfii genotype 2 and 42 isolates of $P$. blaschkeae were used.

Isolates of $P$. zopfii genotype 2 were isolated from individual milk (11 from Italy, 27 from Belgium, 2 from France, and 39 from Poland); pooled and bulk milk (4 from Italy); and water, swabs from milking machine, litter, and feces (12 from Italy). The P. blaschkeae isolates were from individual milk (11 from Italy, 10 from Belgium, and 1 from Poland); bulk milk (2 from Italy); feces and litter (6 from Italy); and milk/water mixture from teats, straw from manhole, and water (11 from Italy).

Primary isolation and culturing of algal isolates were performed according to standardized procedures, essentially described elsewhere (Jagielski et al., 2010). Speciation was based on micromorphological characterization of lactophenol-cotton-blue-stained culture smears and carbohydrate assimilation profiling with the API 20C AUX system (bioMérieux, Marcy l'Etoile, 
France). Genotype-level identification was achieved by genotype-specific PCR (Roesler et al., 2006).

All isolates used in the study are preserved (and available upon request) in the following public repositories: (1) Industrial Yeast Collection DBVPG of the University of Perugia (www.dbvpg.unipg.it); (2) Culture Collection of the Department of Applied Microbiology, Faculty of Biology, University of Warsaw (ZMS-UW), and (3) Collection of the Istituto Zooprofilattico Sperimentale della Lombardia e dell'Emilia Romagna, Piacenza, Italy. Working cultures were prepared by sub-culturing the original isolates on Yeast Peptone Dextrose (YPD) agar (\%: yeast extract 1 , peptone 1 , glucose 2 , and agar 2) medium. Besides, the type strains of both $P$. zopfii genotype $2\left(\mathrm{SAG} 2021^{\mathrm{T}}\right.$ ) and P. blaschkeae (SAG $2064^{\mathrm{T}}$ ) were obtained from the Culture Collection of Algae (SAG), University of Göttingen, Germany, and were used as controls.

The bovine mammary epithelial cell line (BMEUV1) for the 3-(4,5-dimethyl-2-thiazol-2yl)-2,5-diphenyl tetrazolium bromide (MTT) assay was kindly provided by the Istituto Zooprofilattico Sperimentale della Lombardia e dell'Emilia Romagna, Brescia, Italy. The clonal cell line BME-UV1 was established from primary bovine epithelial cells in culture by stable transfection with a plasmid carrying the sequence of the simian virus 40 large $\mathrm{T}$-antigen. It represents a valid model system to examine bovine mammary epithelial proliferation and differentiation and cell-to-cell communication (Zavizion et al., 1996).

\section{Minimum Inhibitory Concentration Determination}

Working solutions of $160 \mathrm{mg} / \mathrm{L}$ of IPBC and AMB (Sigma-Aldrich, St. Louis, MO) were prepared in water:dimethyl sulfoxide (80:20 vol/vol) immediately before use. In the absence of universally accepted procedures or interpretative criteria specific for Prototheca species, Clinical and Laboratory Standard Institute guidelines for broth microdilution for yeasts were followed (CLSI, 2002). Accordingly, MIC of IPBC and AMB were determined at $35^{\circ} \mathrm{C}$ in RPMI 1640 (SigmaAldrich) medium by using 96-well microtiter plates (Corning Inc., New York, NY). Both AMB and IPBC were diluted in RPMI 1640 and the same medium was used to obtain a suspension of the algal inoculum, equal to a $0.5 \mathrm{McF}$ arland turbidity standard (approximately $1.0 \times 10^{6} \mathrm{cfu} / \mathrm{mL}$ ). The concentration of Prototheca spp. cells in the inoculum was checked every time by plating the algae, at appropriate dilutions, on Sabouraud dextrose agar for colony-forming unit measurement. Each time, the cell count was between the values described in the CLSI document (i.e., $1.0-5.0 \times 10^{6} \mathrm{cfu} / \mathrm{mL}$ ).
For each isolate, both AMB and IPBC were tested at doubling concentrations increasing from 0.125 to 8 $\mathrm{mg} / \mathrm{L}$. Isolates that yielded discrepant results were retested for the third time. Only if 2 replications showed identical results was the isolate given the final MIC value of each compound.

To check the method for accuracy, 2 quality control yeast strains were used [i.e., Candida parapsilosis ATCC 22019 and Candida krusei ATCC 6258 (CLSI, 2002)].

The MIC was defined as the lowest concentration of the agent that completely inhibited the algal growth as detected with the naked eye.

\section{2-Dimensional Checkerboard Assay}

To determine any synergistic, additive, or antagonistic effects of the combination of IPBC and AMB, 2-dimensional checkerboard tests were performed in RPMI 1640 in 96-well microtiter plates (Pillai et al., 2005). The principle of the method is illustrated on Figure 1. Briefly, a final volume of $0.1 \mathrm{~mL}$ was used in each well of the microtiter plates and consisted of $0.025 \mathrm{~mL}$ of a solution $4 \times$ of each drug (IPBC and AMB) diluted in RPMI 1640, serially diluted at doubling concentrations increasing along the ordinates and the abscissas with final concentrations ranging from 0.125 to $8 \mathrm{mg} / \mathrm{L}$, and $0.05 \mathrm{~mL}$ of RPMI 1640 containing a suspension of the algal inoculum, equal to a $0.5 \mathrm{McFarland}$ turbidity standard ( $\left.c a .1 \times 10^{6} \mathrm{cfu} / \mathrm{mL}\right)$, prepared from 24 Prototheca spp. isolates (13 of P. zopfii genotype 2 , of which 4 were from Italy, 4 from Belgium, 4 from Poland, and the type strain from SAG; and 11 of $P$. blaschkeae, of which 7 were from Italy, 2 from Belgium, 1 from Poland, and the type strain from SAG) grown in YPD agar plates incubated at $35^{\circ} \mathrm{C}$ for $48 \mathrm{~h}$ under aerobic conditions. The $P$. zopfii genotype 2 isolates used were from individual (9) and pooled milk (1), litter (1), and feces (1), whereas the SAG type strain was isolated from mastitis in a lactating cow. On the other hands, the P. blaschkeae isolates used were from individual milk (5), litter (2), water (2), and straw (1), whereas the SAG type strain was isolated from a human onychomycosis.

The concentrations were set based on our preliminary results for Prototheca spp. strains. They were deduced experimentally, as normally done in such type of studies.

Fractional inhibitory concentrations (FIC) were calculated as follows: FIC of IPBC $=$ MIC of IPBC + $\mathrm{AMB}$ used in combination/MIC of IPBC alone, and $\mathrm{FIC}$ of $\mathrm{AMB}=\mathrm{MIC}$ of AMB + IPBC used in combination/MIC of AMB alone (Pillai et al., 2005). The FIC index $(\boldsymbol{\Sigma}$ FIC $)$ was obtained as follows: $\Sigma$ FIC $=$ FIC of 




Figure 1. Schematic representation of checkerboard analysis of drug interaction between iodopropynyl butylcarbamate (IPBC) and amphotericin B (AMB) against Prototheca sp. isolates used in this study. The results are given for an example Prototheca zopfii genotype 2 isolate. Dark gray and light gray shaded wells represent growth and no growth of the alga, respectively. Asterisks indicate the following: MIC of IPBC $(*)$, MIC of AMB (**), MIC of IPBC in the presence of AMB (***), and MIC of AMB in the presence of IPBC (****). Well H1 is the sterility control (without algal inoculum), and wells A9 to H9 are growth controls (without any drug).

IPBC + FIC of AMB. The combination of IPBC and AMB was considered synergistic when the $\Sigma$ FIC was $\leq 0.5$, additive when the $\Sigma F I C$ was $>0.5$ and $<4$, and antagonistic when the $\Sigma$ FIC was $\geq 4$ (Odds, 2003).

\section{Minimum Algicidal Concentration Determination}

The solutions obtained in 96-well microtiter plates previously employed for MIC determination were used as inocula for minimum algicidal concentration
(MAC; Pillai et al., 2005). After MIC determination, an amount of $0.01 \mathrm{~mL}$ of solutions from the control wells and from the wells corresponding to MIC and 2 -fold, half-fold, and quarter-fold MIC of both IPBC or AMB was spread across the surface of YPD agar plates. More specifically, the following concentrations ranges were used for AMB: 0.5 to $4 \mathrm{mg} / \mathrm{L}$ (1 isolate), 1 to $8 \mathrm{mg} / \mathrm{L}$ (4 isolates), 2 to $16 \mathrm{mg} / \mathrm{L}$ (18 isolates), and 4 to $32 \mathrm{mg} / \mathrm{L}$ (1 isolate); and the following ones for IPBC: 2 to $16 \mathrm{mg} / \mathrm{L}$ (10 isolates) and 4 to $32 \mathrm{mg} / \mathrm{L}$ (14 
isolates). After 48 -h incubation at $35^{\circ} \mathrm{C}$, the number of colonies per plate were counted with a stereoscope. The MAC was determined as the lowest concentration of either IPBC or AMB at which at least $99.9 \%$ of the algal population was killed, when compared with control plates. The MAC of both IPBC and AMB were determined for the same 24 Prototheca sp. isolates (13 of $P$. zopfii genotype 2 and 11 of $P$. blaschkeae, both including their own type strains) that had previously been tested with the 2-dimensional checkerboard assay.

\section{Bovine Mammary Epithelial Cell Line Culturing}

The BME-UV1 cell line was cultured at $37^{\circ} \mathrm{C}$ with $5 \% \mathrm{CO}_{2}$ in 96 -well plates at a density of $2.5 \times 10^{5}$ cells/ $\mathrm{cm}^{2}\left(8 \times 10^{4}\right.$ cells/well $)$. Culture medium contained 40\% Ham's F12, 30\% RPMI 1640, $20 \%$ NCTC 135, $10 \%$ fetal bovine serum (Gibco, Waltham, MA) with $0.1 \%$ lactose, $0.1 \%$ lactalbumin hydrolysate, $1.2 \mathrm{mM}$ glutathione, $10 \mathrm{mg} / \mathrm{L}$ of L-ascorbic acid, $1 \mathrm{mg} / \mathrm{L}$ of hydrocortisone, $1 \mathrm{mg} / \mathrm{L}$ of insulin, $5 \mathrm{mg} / \mathrm{L}$ of transferrin, and $0.5 \mathrm{mg} / \mathrm{L}$ of progesterone (Sigma-Aldrich).

\section{Cytotoxicity Analysis of IPBC on Bovine Mammary Epithelial Cells by MTT Assay}

The MTT assay was performed as described previously (Tomasinsig et al., 2012). Briefly, the BME-UV1 cells were trypsinized and counted. The cell concentration was determined after Trypan blue staining and counting by optical microscope. Cells were seeded in 96 -well plates at a density of $2.5 \times 10^{5} \mathrm{cells} / \mathrm{cm}^{2}(8$ $\times 10^{4}$ cell/well) and incubated for $24 \mathrm{~h}$, followed by a treatment with different concentrations of IPBC $(0.5$, $1,2,4$, and $8 \mathrm{mg} / \mathrm{L})$ or $\mathrm{AMB}(0.125,0.25,0.5,1$, and $2 \mathrm{mg} / \mathrm{L})$ for another $24 \mathrm{~h}$. To determine cell viability, 3-(4,5-dimethyl-2-thiazol-2yl)-2,5-diphenyl tetrazolium bromide (MTT; Sigma-Aldrich), reconstituted in PBS $(5 \mathrm{mg} / \mathrm{L})$ was added to each well and incubated for 2 and $4 \mathrm{~h}$. After incubation, the MTT formazan product (an insoluble purple compound produced by the reduction of the tetrazolium dye MTT) was dissolved in 0.1 $M \mathrm{HCl}$ in anhydrous isopropanol and the absorbances at $570 \mathrm{~nm}\left(\mathrm{~A}_{570}\right)$ and $690 \mathrm{~nm}\left(\mathrm{~A}_{690}\right)$ were measured (Multiskan Go, Thermo Scientific, Milan, Italy). The background absorbance $\left(\mathrm{A}_{690}\right)$ was subtracted from the $\mathrm{A}_{570}$ measurement and the cell viability was calculated using the following formula: cell viability $(\%)=(\mathrm{OD}$ of drug-treated sample/OD of untreated sample) $\times 100$.

The final results were given as medians and first and third interquartiles. The cytotoxic effect of both IPBC and $\mathrm{AMB}$ at concentrations increasing from 0.125 to $2 \mathrm{mg} / \mathrm{L}$ for $\mathrm{AMB}$, and from 0.5 to $8 \mathrm{mg} / \mathrm{L}$ for IPBC, was assessed in triplicate. The control samples (with no drug) were also examined in triplicate.

\section{Statistical Analysis}

Nonparametric tests of Wilcoxon and Mann-Whitney were used to compare IPBC and AMB with respect to their $\mathrm{MIC}_{50 / 90}$ and $\mathrm{MAC}_{50 / 90}$ values, and toxicities, at different exposure times. The Wilcoxon test was used to compare 2 dependent samples (e.g., MIC of IPBC and AMB for different Prototheca sp. populations), whereas the Mann-Whitney test was applied to independent samples (e.g., for comparing MIC of AMPB or IPBC between strains of different Prototheca sp. populations).

The differences in the cell viabilities after IPBC or $\mathrm{AMB}$ treatment at different concentrations and time of exposure, as well as differences in the cell viabilities between the 2 drugs applied at the same concentrations $(0.5,1$, and $2 \mathrm{mg} / \mathrm{L})$ and for the same time periods (2 and $4 \mathrm{~h}$ ) were assessed with the Wilcoxon test.

Data were analyzed with SPSS statistical software package (ver. 21.0; SPSS Inc., IBM Co., Armonk, New York, NY). A $P$-value $<0.05$ was considered significant.

\section{RESULTS}

The MIC ranges, MIC medians and first and third quartiles, and $\mathrm{MIC}_{50}$ and $\mathrm{MIC}_{90}$ of IPBC and $\mathrm{AMB}$ tested against $P$. zopfii genotype 2 and $P$. blaschkeae isolates are shown in Table 1. Overall, when compared with IPBC, AMB exhibited a higher activity against Prototheca spp. The $\mathrm{MIC}_{50}$ and $\mathrm{MIC}_{90}$ values for IPBC were 4 and $8 \mathrm{mg} / \mathrm{L}$ versus 0.5 and $1 \mathrm{mg} / \mathrm{L}$ for $\mathrm{AMB}$, respectively. This difference, that is, higher $\mathrm{MIC}_{50}$ and $\mathrm{MIC}_{90}$ values for IPBC than AMB, was statistically significant $(P<0.001)$. Interestingly, the MIC profiles differed between $P$. zopfii genotype 2 and $P$. blaschkeae, with the latter species being more susceptible to both compounds used in the study (Table 1). This difference was more pronounced for IPBC, as its $\mathrm{MIC}_{50}$ and $\mathrm{MIC}_{90}$ values were 4 and $8 \mathrm{mg} / \mathrm{L}$ for $P$. zopfii genotype 2 and only 1 and $2 \mathrm{mg} / \mathrm{L}$ for $P$. blaschkeae. The $\mathrm{MIC}_{50}$ and $\mathrm{MIC}_{90}$ for IPBC were significantly $(P<0.001)$ higher for $P$. zopfii genotype 2 than $P$. blaschkeae.

Interestingly, 40 (41.7\%) out of 96 P. zopfii genotype 2 isolates had their MIC of IPBC equal to the highest concentration tested $(8 \mathrm{mg} / \mathrm{L})$ and no one had a MIC above this value.

The IPBC and AMB, when combined, appeared to exhibit an increased algicidal activity by 2 - to 8 -fold, against both $P$. zopfii genotype 2 and $P$. blaschkeae (Table 2). The $\Sigma$ FIC results for the combination IPBC 


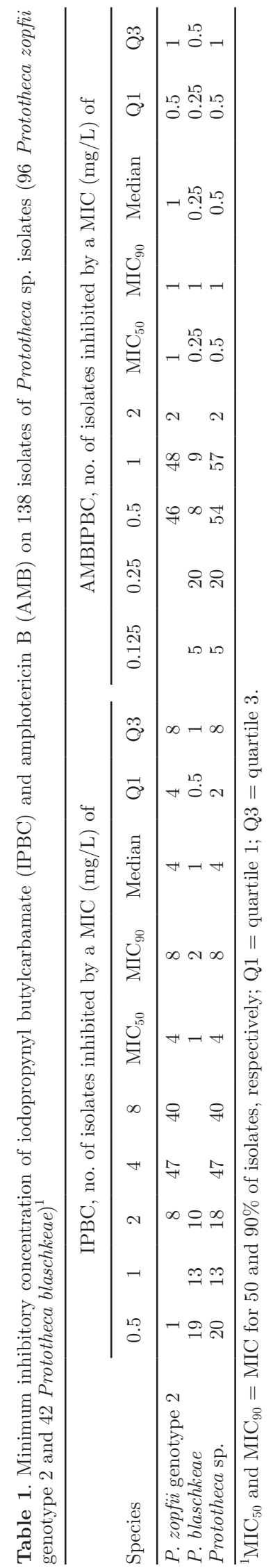

+ AMB showed synergistic activity $(\Sigma \mathrm{FIC}=0.5)$ only against $3 P$. zopfii genotype 2 isolates $(12.5 \%$ of all Prototheca isolates tested). For all the remaining isolates $(21 ; 87.5 \%)$, this combination produced only an additive effect $(\Sigma \mathrm{FIC}>0.5)$.

The MAC of IPBC and AMB were determined for 24 Prototheca isolates, including $13 P$. zopfii genotype 2 and 11 P. blaschkeae isolates (Table 3). Both IPBC and AMB exhibited the ability to kill Prototheca spp., yet the former agent was shown to be more algicidal because its MAC values were much closer to those of MIC. The $\mathrm{MAC}_{90}$ value of IPBC was twice the $\mathrm{MIC}_{90}$ value ( 8 vs. $16 \mathrm{mg} / \mathrm{L}$ ), whereas an 8 -fold increase of the $\mathrm{MIC}_{90}$ value was algicidal in case of AMB (1 vs. 8 $\mathrm{mg} / \mathrm{L})$. No significant interspecies differences were observed in MAC values with either compound $(P>0.2)$.

The MTT assay results showed both IPBC and $\mathrm{AMB}$, at the concentrations employed in the study, to be nontoxic to the mammary gland cells (cell viability $>90 \%$; Figure 2). Notably, only IPBC at the highest concentration (i.e., $8 \mathrm{mg} / \mathrm{L}$ ) exerted slight cytotoxic effect on BME-UV1 cell line (mean cell viability: $88.54 \pm$ 3.88 and $90.66 \pm 3.0$, after 2 and $4 \mathrm{~h}$ of MTT treatment, respectively). No statistically significant differences $(P$ $\geq 0.125$ ) were observed in the cell viabilities after IPBC or AMB treatment regardless of whether the time of exposure was 2 or $4 \mathrm{~h}$. Likewise, no significant differences $(P>0.05)$ in the cell viabilities were observed between the 2 drugs applied at the same concentrations $(0.5,1$, and $2 \mathrm{mg} / \mathrm{L})$ and for the same time periods (2 and $4 \mathrm{~h}$; Figure 2).

\section{DISCUSSION}

Due to the lack of susceptibility of Prototheca spp. to a vast array of antimicrobials currently in use in veterinary medicine, treatment of bovine protothecosis is sometimes considered either futile or nonbeneficial (Castagna de Vargas et al., 1998; Buzzini et al., 2008; Jagielski et al., 2012). Accordingly, the common idea about the lack of drugs with proven clinical efficacy against protothecal mastitis leaves culling of infected animals as the privileged measure to contain and prevent the infection from spreading within the dairy herd. Consequently, there is a continuing need for new compounds that would be both highly active against Prototheca spp. and nontoxic to the udder tissue.

Only anecdotal studies have documented so far positive clinical outcome in Prototheca-infected cows after administration of pharmacological treatment (VanDamme, 1983; Bergmann, 1993; Brito and Veiga, 1997; Chang et al., 2013). A promising group of antimicrobial agents are organic iodine preparations, which are currently available under 2 main formulations: (1) aqueous 
Table 2. Fractional inhibitory concentration (FIC) of iodopropynyl butylcarbamate (IPBC) and amphotericin B (AMB) on 24 Prototheca sp. isolates (13 Prototheca zopfii genotype 2 and 11 Prototheca blashkeae)



or alcoholic solutions (e.g., iodine tincture and Lugol's solution), and (2) iodophores [e.g., polyvinylpyrrolidoneiodin (PVP-I)]. Both are well-known agents exhibiting a broad spectrum of antiviral, antibacterial, antifungal, and anti-Prototheca activity (McDonnell and Russell, 1999; Salerno et al., 2010; Lassa et al., 2011; Sobukawa et al., 2011; Gonçalves et al., 2015; Răpuntean et al., 2015). Iodophores, being complexes of elemental iodine linked to carrier organic molecules acting as solubilizers, currently lack drawbacks occurring in aqueous or alcoholic solutions (i.e., a high degree of instability, skin staining, and irritation).

The present study is the first report on the sensitivity of Prototheca spp. to IPBC, which is another widely used iodophor. The obtained results showed IPBC to have a superior anti-Prototheca activity than that previously observed for iodine solutions, which exhibited MIC from 100 to $625 \mathrm{mg} / \mathrm{L}$, and MAC from 6,250 to $12,500 \mathrm{mg} / \mathrm{L}$, respectively (Salerno et al., 2010; Lassa et al., 2011; Krukowski et al., 2013; Gonçalves et al., 2015). On the other hand, PVP-I showed a higher algaecide action
$\left(\mathrm{MAC}_{90} \leq 1.63 \mathrm{mg} / \mathrm{L}\right)$ when compared with our results for IPBC (Sobukawa et al., 2011). Nevertheless, given that iodophoric veterinary preparations contain 0.25 to $1 \%$ available iodine, which translates approximately into 2,500 to $10,000 \mathrm{mg} / \mathrm{L}$, the MAC for IPBC observed in this study was much below this range. Results herein reported for IPBC are consistent with those reported for PVP-I by Sobukawa et al. (2011), who found that commercial formulas contains organoiodine compounds at concentrations 500 to 1,000 higher than those sufficient to kill Prototheca spp. isolates.

In this study, the Prototheca isolates were susceptible to $\mathrm{AMB}$ at a median concentration of $0.5 \mathrm{mg} / \mathrm{L}$, with $\mathrm{MIC}_{50}$ and $\mathrm{MIC}_{90}$ of 0.5 and $1 \mathrm{mg} / \mathrm{L}$, respectively, in agreement with results reported previously for AMB (Marques et al., 2006; Tortorano et al., 2008; Sobukawa et al., 2011; Jagielski et al., 2012). Analogously to the study of Jagielski et al. (2012) isolates of P. blaschkeae were more susceptible to AMB than isolates of $P$. zopfii genotype 2. Interestingly, the same difference, but even more pronounced, was noted for IPBC. Differ-

Table 3. Minimum algicidal concentration (MAC) of iodopropynyl butylcarbamate (IPBC) and amphotericin B (AMB) on 24 Prototheca sp. isolates (13 Prototheca zopfii genotype 2 and 11 Prototheca blaschkeae) ${ }^{1}$

\begin{tabular}{|c|c|c|c|c|c|c|c|}
\hline \multirow[b]{2}{*}{ Antimicrobial agent } & \multirow[b]{2}{*}{ Species } & \multicolumn{4}{|c|}{$\begin{array}{c}\text { No. of isolates with MAC } \\
(\mathrm{mg} / \mathrm{L}) \text { of }\end{array}$} & \multirow[b]{2}{*}{$\mathrm{MAC}_{50}$} & \multirow[b]{2}{*}{$\mathrm{MAC}_{90}$} \\
\hline & & 2 & 4 & 8 & 16 & & \\
\hline \multirow[t]{3}{*}{$\overline{\mathrm{IPBC}}$} & P. zopfii genotype 2 & & & 4 & 9 & 16 & 16 \\
\hline & P. blaschkeae & & & 6 & 5 & 8 & 16 \\
\hline & Prototheca sp. & & & 10 & 14 & 16 & 16 \\
\hline \multirow[t]{3}{*}{$\mathrm{AMB}$} & P. zopfii genotype 2 & & 3 & 9 & 1 & 8 & 8 \\
\hline & P. blaschkeae & 1 & 1 & 9 & & 8 & 8 \\
\hline & Prototheca sp. & 1 & 4 & 18 & 1 & 8 & 8 \\
\hline
\end{tabular}

${ }^{1} \mathrm{MAC}_{50}$ and $\mathrm{MAC}_{90}=\mathrm{MAC}$ for 50 and $90 \%$ of isolates, respectively. 

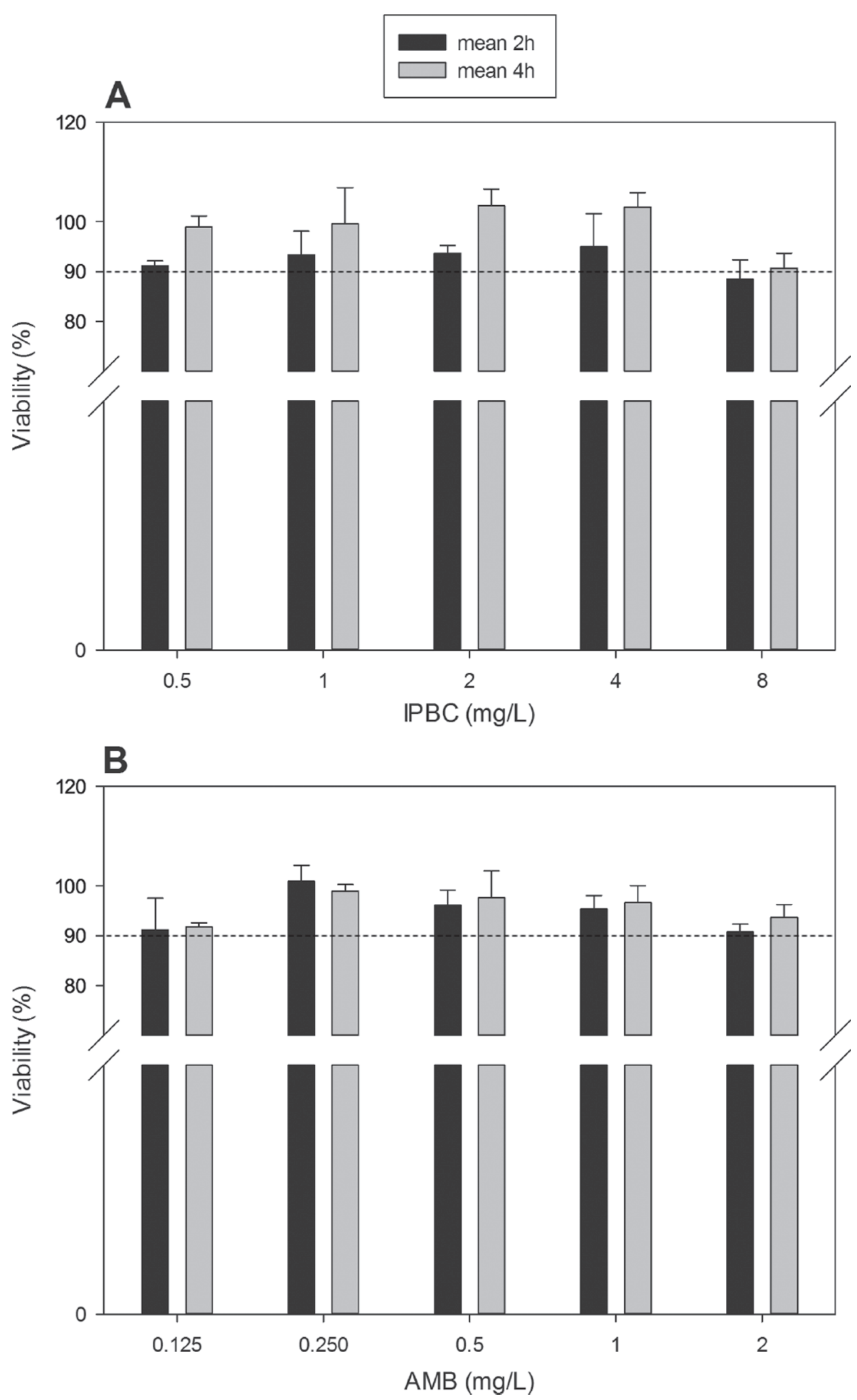

Figure 2. Results of 3-(4,5-dimethyl-2-thiazol-2yl)-2,5-diphenyl tetrazolium bromide (MTT) assay on the cytotoxicity of both iodopropynyl butylcarbamate (IPBC) and amphotericin B (AMB) at concentrations increasing from 0.125 to $8 \mathrm{mg} / \mathrm{L}$ on a bovine mammary epithelial cell line (BME-UV1). Dashed lines = cell viability of $90 \%$. Error bars indicated the variability of data of 3 separate determinations. 
ences in the drug susceptibility patterns have recently been found between $P$. zopfii isolates from different geographical regions (Morandi et al., 2016).

In the last decades AMB has been tested in association with many other drugs and a synergistic antifungal effect has been sometimes found (Lee et al., 1975; Odds, 1982; Srimuang et al., 2000; Ryder and Leitner, 2001; Zarrin and Najafi, 2007; Oliver et al., 2008; Drogari-Apiranthitou et al., 2012). In agreement with Odds (2003), the combination of IPBC and AMB was predominantly additive and only in $3 P$. zopfii genotype 2 isolates was a synergistic interaction found. Mechanistically, we might speculate that in such instances: (1) AMB, by disrupting membrane structure through binding to ergosterol, may facilitate and accelerate the cellular uptake of IPBC, and (2) IPBC, by interacting with the membrane phospholipids, may enhance the exposure of ergosterol, thus increasing its affinity and binding to AMB.

Anyway, the simultaneous use of both IPBC and AMB reduced one another's MIC values by up to 8-fold, rendering their positive interaction (additive or synergistic) mutually reinforcing, although synergy between the 2 compounds was found only in about $12 \%$ of all Prototheca isolates tested. This evidence can be considered positive because AMB, especially when administrated in its conventional deoxycholate formulation, may inflict severe side effects on human and animal cells, limiting dose escalation and clinical efficacy. Analogously, the misuse of AMB as a food preservative or as a component of a treatment regimen for dairy cows is always potentially hazardous to human health, as it may generate resistance to auto- or allochthonous microflora (or both). Dalhoff and Levy (2015) reported that the addition of the polyene natamycin to foodstuffs is completely different from its direct use in veterinary medicine, because in the latter case microbial genes inducing antibiotic resistance may be transferred from treated animals to human beings via the food chain, whereas the use of natamycin as a food additive may expose the human intestinal flora directly to the selective pressure.

Surprisingly, both IPBC and AMB induced no significant toxic effect (cell viability $>90 \%$ ) on mammary epithelial cells at concentrations equivalent to those inhibiting growth of Prototheca spp., which is different from what has been reported on AMB. The drug has often been associated with adverse effects, including infusion-related reactions, and nephro- and hepatotoxicity, although the risk for these side effects seems to be significantly reduced when the daily clinical dosage of AMB is below $1 \mathrm{mg} / \mathrm{kg}$ (Hamill, 2013). In the case of IPBC, only sporadic cases of allergic contact dermatitis from IPBC-containing products, with an iodophore concentration of $0.05 \%$ (approximately $500 \mathrm{mg} / \mathrm{L}$, more than 60 times higher than the highest concentration employed in this study) have been reported (Bryld et al., 2001).

In conclusion, the key findings from this study can be summarized in 3 points: (1) an anti-Prototheca effect of the iodoorganic compound IPBC was demonstrated, (2) the combination of IPBC with AMB enhanced each other's effect, in either a synergistic or additive manner, and (3) both agents, used at concentrations equivalent to MIC values against Prototheca spp., presented no toxicity for the mammalian epithelial cells.

With all the limitations that the in vitro assays may have, the data herein reported support the use of IPBC, either alone or in combination with AMB, as a treatment option for Prototheca infections in veterinary medicine.

\section{ACKNOWLEDGMENTS}

The authors are grateful to Maura Ferrari (Istituto Zooprofilattico Sperimentale della Lombardia e dell'Emilia Romagna, Brescia, Italy) for providing BME-UV1 cells, and to Luca Medulla from Agrilab (Centallo, Cuneo, Italy) for providing a few P. blaschkeae isolates. This work was supported by the Italian Ministry of Health, Rome, Italy (Progetti di Ricerca Corrente 2014-Contract No: IZSUM 01/2014 RC) and by the National Science Centre (Krakow, Poland) within the "SONATA" funding scheme (Contract No: 2014/15/D/NZ7/01797).

\section{REFERENCES}

Aalbaek, B., H. E. Jensen, and A. Hude. 1998. Identification of Prototheca from bovine mastitis in Denmark. APMIS 106:483-488.

Bennet, J. E. 2005. Antimicrobial agents. Antifungal agents. Pages 1225-1242 in The Pharmacological Basis of Therapeutics. L. L. Brunton, J. S. Lazo, and K. L. Parker, ed. 11th ed. Goodman and Gilman's, McGraw-Hill Med. Div., New York, NY.

Bergmann, A. 1993. Experimental Prototheca mastitis in cattle and therapy with tetramisole hydrochloride. Berl. Munch. Tierarztl. Wochenschr. 106:257-260.

Bouari, C., P. Bolfa, G. Borza, G. Nadăș, C. Cătoi, and N. Fiț. 2014 Antimicrobial activity of Mentha piperita and Saturenja hortensis in a murine model of cutaneous protothecosis. J. Mycol. Med. 24:34-43

Bozzo, G., E. Bonerba, A. Di Pinto, G. Bolzoni, E. Ceci, A. Mottola, G. Tantillo, and V. Terio. 2014. Occurrence of Prototheca spp. in cow milk samples. New Microbiol. 37:459-464.

Brito, M. A. V. P., and V. M. O. Veiga. 1997. Clinical bovine mastitis caused by Prototheca zopfii: A case study. Cienc. Rural 27:681-684.

Bryld, L. E., T. Agner, and T. Menné. 2001. Allergic contact dermatitis from 3-iodo-2-propynyl-butylcarbamate (IPBC)-An update. Contact Derm. 44:276-278.

Buzzini, P., B. Turchetti, E. Branda, M. Goretti, M. Amici, P. E. Lagneau, L. Scaccabarozzi, V. Bronzo, and P. Moroni. 2008. Largescale screening of the in vitro susceptibility of Prototheca zopfii towards polyene antibiotics. Med. Mycol. 46:511-514. 
Buzzini, P., B. Turchetti, R. Facelli, R. Baudino, F. Cavarero, L. Mattalia, P. Mosso, and A. Martini. 2004. First large-scale isolation of Prototheca zopfii from milk produced by dairy herds in Italy. Mycopathologia 158:427-430.

Castagna de Vargas, A., A. Lazzari, J. M. Santurio, S. H. Alves, G. Ferreira, and L. C. Kreutz. 1998. Isolation of Prototheca zopfii from a case of bovine mastitis in Brazil. Mycopathologia 142:135-137.

Chang, R., Q. Yang, G. Liu, Y. Liu, B. Zheng, J. Su, and B. Han. 2013. Treatment with gentamicin on a murine model of protothecal mastitis. Mycopathologia 175:241-248.

CLSI (Clinical and Laboratory Standard Institute). 2002. Reference method for broth dilution antifungal susceptibility testing of yeasts: Approved standard. 2nd ed. Document M27-A2. Wayne, PA.

Cunha, L. T., S. M. P. Pugine, M. R. M. Silva, E. J. Costa, and M. P. De Melo. 2010. Microbicidal action of indole-3-acetic acid combined with horseradish peroxidase on Prototheca zopfii from bovine mastitis. Mycopathologia 169:99-105.

Dalhoff, A. A. H., and S. B. Levy. 2015. Does use of the polyene natamycin as a food preservative jeopardise the clinical efficacy of amphotericin B? A word of concern. Int. J. Antimicrob. Agents 45:564-567.

Drogari-Apiranthitou, M., F. D. Mantopoulou, A. Skiada, L. Kanioura, M. Grammatikou, G. Vrioni, A. Mitroussia-Ziouva, A. Tsakris, and G. Petrikkos. 2012. In vitro antifungal susceptibility of filamentous fungi causing rare infections: Synergy testing of amphotericin B, posaconazole and anidulafungin in pairs. J. Antimicrob. Chemother. 67:1937-1940.

Gao, J., H. Q. Zhang, J. Z. He, Y. H. He, S. M. Li, R. G. Hou, Q. X. Wu, Y. Gao, and B. Han. 2012. Characterization of Prototheca zopfii associated with outbreak of bovine clinical mastitis in herd of Beijing, China. Mycopathologia 173:275-281.

Gonçalves, J. L., S. H. I. Lee, E. de Paula Arruda, D. Pedroso Galles, V. Camargo Caetano, C. A. Fernandes de Oliveira, A. M. Fernandes, and M. Veiga dos Santos. 2015. Biofilm-producing ability and efficiency of sanitizing agents against Prototheca zopfii isolates from bovine subclinical mastitis. J. Dairy Sci. 98:3613-3621.

Grzesiak, B., A. Głowacka, H. Krukowski, A. Lisowski, H. Lassa, and M. Sienkiewicz. 2016. The in vitro efficacy of essential oils and antifungal drugs against Prototheca zopfii. Mycopathologia 181:609-615.

Hamill, R. J. 2013. Amphotericin B formulations: A comparative review of efficacy and toxicity. Drugs 73:919-934.

Jagielski, T., P. Buzzini, H. Lassa, E. Malinowski, E. Branda, B. Turchetti, A. Polleichtner, U. Roesler, P. E. Lagneau, S. Marques, E. Silva, G. Thompson, R. Stachowiak, and J. Bielecki. 2012. Multicentre Etest evaluation of in vitro activity of conventional antifungal drugs against European bovine mastitis Prototheca spp. isolates. J. Antimicrob. Chemother. 67:1945-1947.

Jagielski, T., and P. E. Lagneau. 2007. Protothecosis. A pseudofungal infection. J. Mycol. Med. 17:261-270.

Jagielski, T., H. Lassa, J. Ahrholdt, E. Malinowski, and U. Roesler. 2011. Genotyping of bovine Prototheca mastitis isolates from Poland. Vet. Microbiol. 149:283-287.

Jagielski, T., H. Lassa, J. Ahrholdt, U. Roesler, and E. Malinowski. 2010. Molecular characterization of Polish Prototheca zopfii mastitis isolates and first isolation of Prototheca blaschkeae in Poland. Pol. J. Vet. Sci. 13:725-729.

Janosi, S., F. Ratz, G. Szigeti, M. Kulcsár, J. Kerényi, T. Laukó, F. Katona, and G. Huszenicza. 2001. Review of the microbiological, pathological and clinical aspects of bovine mastitis caused by the alga Prototheca zopfii. Vet. Q. 23:58-61.

Krukowski, H., A. Lisowski, B. Nowaowicz-Dębek, and L. Wlazło. 2013. Susceptibility of Prototheca zopfii strains isolated from cows with mastitis to chlorhexidine and iodine. Turk. J. Vet. Anim. Sci. $37: 106-108$.

Lagneau, P. E. 1996. First isolation of Prototheca zopfii in bovine mastitis in Belgium. J. Mycol. Med. 6:145-148.

Lassa, H., T. Jagielski, and E. Malinowski. 2011. Effect of different heat treatments and disinfectants on the survival of Prototheca zopfii. Mycopathologia 171:177-182.
Lee, W. S., M. D. Lagios, and R. Leonards. 1975. Wound infection by Prototheca wickerhamii, a saprophytic alga pathogenic for man. J. Clin. Microbiol. 2:62-66.

Maier, L. E., H. P. Lampel, T. Bhutani, and S. E. Jacob. 2009. Hand dermatitis: A focus on allergic contact dermatitis to biocides. Dermatol. Clin. 27:251-264.

Marques, S., E. Silva, J. Carvalheira, and G. Thompson. 2006. Short communication: In vitro antimicrobial susceptibility of Prototheca wickerhamii and Prototheca zopfii isolated from bovine mastitis. J. Dairy Sci. 89:4202-4204.

Masuda, M., N. Hirose, and T. Ishikawa. 2016. Prototheca miyajii sp. nov., isolated from a patient with systemic protothecosis. Int. J. Syst. Evol. Microbiol. 66:1510-1520.

McDonnell, G., and A. D. Russell. 1999. Antiseptics and disinfectants: Activity, action, and resistance. Clin. Microbiol. Rev. 12:147-179.

Melville, P. A., N. R. Benites, I. L. Sinhorini, and O. E. Costa. 2002. Susceptibility and features of the ultrastructure of Prototheca zopfii following exposure to copper sulphate, silver nitrate and chlorexidine. Mycopathologia 156:1-7.

Morandi, S., P. Cremonesi, E. Capra, T. Silvetti, M. Decimo, V. Bianchini, A. C. Alves, A. C. Vargas, G. M. Costa, M. G. Ribeiro, and M. Brasca. 2016. Molecular typing and differences in biofilm formation and antibiotic susceptibilities among Prototheca strains isolated in Italy and Brazil. J. Dairy Sci. 99:6436-6445.

Odds, F. C. 1982. Interactions among amphotericin B, 5-fluorocytosine, ketoconazole, and miconazole against pathogenic fungi in vitro. Antimicrob. Agents Chemother. 22:763-770.

Odds, F. C. 2003. Synergy, antagonism, and what the chequerboard put between them. J. Antimicrob. Chemother. 52:1.

Oliver, B. G., P. M. Silver, C. Marie, S. J. Hoot, S. E. Leyde, and T. C. White. 2008. Tetracycline alters drug susceptibility in Candida albicans and other pathogenic fungi. Microbiology 154:960-970.

Pillai, S. K., R. C. Moellering, and G. M. Eliopoulos. 2005. Antimicrobial combination. Pages 365-424 in Antibiotics in Laboratory Medicine. 5th ed. V. Lorian, ed. Williams and Wilkins, Philadelphia, PA.

Răpuntean, S., G. Răpuntean, F. Chirilă, N. I. Fit, and G. C. Nadas. 2015. The effect of iodine based products on unicellular algae from genus Prototheca. Bull. UASVM 72:306-313.

Ricchi, M., C. De Cicco, P. Buzzini, G. Cammi, N. Arrigoni, M. Cammi, and C. Garbarino. 2013. First outbreak of bovine mastitis caused by Prototheca blaschkeae. Vet. Microbiol. 162:997-999.

Ricchi, M., M. Goretti, E. Branda, G. Cammi, C. Garbarino, B. Turchetti, P. Moroni, N. Arrigoni, and P. Buzzini. 2010. Molecular characterization of Prototheca strains isolated from Italian dairy herds. J. Dairy Sci. 93:4625-4631.

Roesler, U., A. Möller, A. Hensel, D. Baumann, and U. Truyen. 2006. Diversity within the current algal species Prototheca zopfii: a proposal for two Prototheca zopfii genotypes and description of a novel species, Prototheca blaschkeae sp. nov. Int. J. Syst. Evol. Microbiol. $56: 1419-1425$.

Ryder, N. S., and I. Leitner. 2001. Synergistic interaction of terbinafine with triazoles or amphotericin B against Aspergillus species. Med. Mycol. 39:91-95.

Salerno, T., M. G. Ribeiro, H. Langoni, A. K. Siqueira, E. O. Costa, P. A. Melville, V. F. Bueno, A. A. Yamamura, U. Roesler, and A. V. da Silva. 2010. In vitro algaecide effect of sodium hypochlorite and iodine based antiseptics on Prototheca zopfii strains isolated from bovine milk. Res. Vet. Sci. 88:211-213.

Satoh, K., K. Ooe, H. Nagayama, and K. Makimura. 2010. Prototheca cutis sp. nov., a newly discovered pathogen of protothecosis isolated from inflamed human skin. Int. J. Syst. Evol. Microbiol. 60:1236-1240.

Scaccabarozzi, L., B. Turchetti, P. Buzzini, G. Pisoni, L. Bertocchi, N. Arrigoni, P. Boettcher, V. Bronzo, and P. Moroni. 2008. Short communication: isolation of Prototheca species strains from environmental sources in dairy herds. J. Dairy Sci. 91:3474-3477.

Shahid, M., T. Ali, L. Zhang, R. Hou, S. Zhang, L. Ding, D. Han, Z. Deng, A. Rahman, and B. Han. 2016. Characterization of Prototheca zopfii genotypes isolated from cases of bovine mastitis and cow barns in China. Mycopathologia 181:185-195. 
Sobukawa, H., M. Watanabe, R. Kano, T. Ito, M. Onozaki, A. Hasegawa, and H. Kamata. 2011. In vitro algaecide effect of disinfectants on Prototheca zopfii genotypes 1 and 2. J. Vet. Med. Sci. 73:1527-1529.

Srimuang, S., C. Prariyachatigul, A. Chaiprasert, W. Rungsipanuratn, and D. Tanphaichitra. 2000. Antifungal drug combinations for Cryptococcus neoformans and Prototheca spp. J. Med. Assoc. Thai. 83:57-60.

Steinberg, D. C. 2002. Iodopropynyl butylcarbamate as a preservative. Am. J. Contact Dermat. 13:207-208.

Stenner, V. J., B. Mackay, T. King, V. R. Barrs, P. Irwin, L. Abraham, N. Swift, N. Langer, M. Bernays, E. Hampson, P. Martin, M. B. Krockenberger, K. Bosward, M. Latter, and R. Malik. 2007. Protothecosis in 17 Australian dogs and a review of the canine literature. Med. Mycol. 45:249-266.

Sweetman, S. C. 2005. Martindale: The Complete Drug Reference, 34th ed. The Pharmaceutical Press, London, UK.

Tomasinsig, L., B. Skerlavaj, M. Scarsini, F. Guida, R. Piccinini, A. Tossi, and M. Zanetti. 2012. Comparative activity and mechanism of action of three types of bovine antimicrobial peptides against pathogenic Prototheca spp. J. Pept. Sci. 18:105-113.

Tortorano, A. M., A. Prigitano, G. Dho, R. Piccinini, V. Daprà, and M. A. Viviani. 2008. In vitro activity of conventional antifungal drugs and natural essences against the yeast-like alga Prototheca. J. Antimicrob. Chemother. 61:1312-1314.

Tsuji, H., R. Kano, A. Hirai, M. Murakami, T. Yanai, Y. Namihira, J. Chiba, and A. Hasegawa. 2006. An isolate of Prototheca wickerhamii from systemic canine protothecosis. Vet. Microbiol. 118:305-311.

VanDamme, D. M. 1983. Use of miconazole in treatment for bovine mastitis. Vet. Med. 78:1425-1427.

Zarrin, M., and M. R. Najafi. 2007. In vitro activities of amphotericin $\mathrm{B}$ in combination with rifampin against Aspergillus species. Pak. J. Med. Sci. 23:323-325.

Zavizion, B., M. van Duffelen, W. Schaeffer, and I. Politis. 1996. Establishment and characterization of a bovine mammary epithelial cell line with unique properties. In Vitro Cell. Dev. Biol. Anim. 32:138-148. 